\title{
O LUGAR DA FUNÇ̃̃o POÉTICA NA POLI(A)FONIA dO OBJeto VOZ EM PsicanÁlISE
}

Conrado Ramos

Resumo

Este trabalho, produto de um cartel de uma Escola de Psicanálise, pretende desenvolver a concepção do objeto voz como objeto perdido da pulsão invocante, segundo Jacques Lacan, e buscar as manifestações subjetivas e formas clínicas nas quais pode-se encontrar a recuperação da voz como objeto mais-de-gozar. Neste percurso discute-se a alucinação sonora, a ruminação obsessiva e o insulto entre outros fenômenos. Num segundo momento discute-se o lugar da função poética na interpretação psicanalítica, tomando a materialidade sonora, a assonância e os afetos provocados pela poesia como recuperação imaginária de um gozo perdido. Conclui-se que, uma vez que a voz se faça estruturalmente objeto perdido, não há emissão significante que não carregue um enigma, não há endereçamento não atravessado pelo oracular, não há comunicação em que o equívoco não seja possível.

Abstract

This work is the product of a cartel of a Psychoanalysis School and aims to develop the design of the object voice as a lost object of the invoking drive, according to Jacques Lacan, and to seeks subjective manifestations and clinical forms in which one can find recovery of the voice as the more-to-enjoy object. In this course, we discuss the sonic hallucination, obsessive rumination and insult, among other phenomena. Following that, we discuss the place of the poetic function in psychoanalytic interpretation, taking the sonic materiality, assonance and affections caused by poetry as an imaginary recovery of lost enjoyment. We conclude that, once the voice is structurally turned into a lost object, there is no significant emission that does not carry an enigma, there no address that is not crossed by the oracular, and there is no communication in which mistake is not possible.
Palavras-chave: cartel; objeto voz; função poética; Psicanálise; Jacques Lacan.

Keywords:

cartel; object voice; poetic function; Psychoanalysi s; Jacques Lacan. 


\begin{abstract}
Para mim, permanece um enigma, como, aliás, muitas outras coisas, o fato de que aparentemente os gritos de socorro não sejam percebidos por outras pessoas: a sensação acústica que atinge meu ouvido, centenas de vezes por dia, é tão nítida que de modo algum se poderá falar de uma ilusão dos sentidos. Aos "gritos de socorro" autênticos se acrescenta imediatamente a frase decorada: "Se ao menos cessassem estes gritos de socorro." (Daniel Paul Schreber)
\end{abstract}

Olhar-me, imploras, anelante,

Ouvir-me a voz, ver-me o fulgor;

Cedo a essa invocação possante,

Eis-me! - Que mísero pavor

Te invade, ó super-homem? [...]

(O Gênio, em Fausto I [486-490], Goethe)

\title{
Introdução
}

Este texto é fruto de um cartel, dispositivo de estudo e de trabalho proposto por Jacques Lacan (1964/2003) no ato de fundação de sua Escola de Psicanálise e que consiste num pequeno grupo formado de três a cinco pessoas, mais-uma, encarregada não de completar o grupo, mas justamente de descompletá-lo, relançando questões, rompendo certezas e interrogando consensos, de modo a manter aberto um furo em relação ao saber. Um cartel, assim, não é um grupo de estudos que se reúne em torno de um mestre/professor, mas um conjunto de pessoas interessadas num mesmo tema e dispostas a construir um saber a partir desse laço especial de trabalho no qual as dúvidas e experiências de cada um têm lugar e não encontram respostas e certezas de alguém a quem se demandaria uma resposta final. Trata-se, assim, de um grupo que se propõe a suportar e mesmo a manter a incompletude própria ao saber e ao inconsciente (donde a importante função do mais-um).

Embora reunidos em torno de um tema comum, cada membro do cartel deve apresentar uma questão própria, seu interesse particular dentro do tema comum, questão que norteará suas pesquisas e discussões dentro das reuniões e no trabalho de pesquisa que geralmente acontece fora dos horários de reunião do cartel.

É próprio do funcionamento do cartel que se organizem reuniões periódicas pelo período de dois anos, ao final dos quais espera-se de cada membro, inclusive do mais-um, a produção de um texto sobre o tema a ser compartilhado não só com os colegas, mas com a comunidade de sua Escola. Quando um cartel assim chega ao fim, aqueles laços se dissolvem e seus participantes realizam uma permuta buscando novos colegas para formarem novos cartéis.

Com este dispositivo, Lacan objetivou descentralizar a produção do saber e dificultar a constituição de hierarquias rígidas de mestres e discípulos, transformando a Escola naquilo que resulta de um fazer democrático que pede a cada um que coloque algo de si, seja levantando questões, seja debatendo com colegas, seja produzindo textos para a comunidade. A função do 
mais-um e o tempo de duração de um cartel com sua posterior dissolução, além disso, evitam cristalizações grupais e permitem que elementos próprios do discurso psicanalítico sejam colocados nos laços de trabalho, fundados também em transferências (entendidas em seu sentido psicanalítico).

O cartel que inspirou a produção deste texto e se encerra em dezembro de 2014 teve como tema a voz e conta com os seguintes participantes, com seus respectivos temas: Dominique Fingermann (a voz do poema), Rita Vogelaar (voz de analista), Conrado Ramos (como a função poética opera com o que não é linguagem e quais os seus lugares na direção do tratamento?), Luis Guilherme Coelho Mola (a voz como borda do sentido) e Beatriz Oliveira (mais-um) (o que transmite a voz?).

Durante dois anos, com encontros mensais, além das diversas referências que cada um trouxe aos encontros e estudou pessoalmente, trabalhamos juntos principalmente três livros, quais sejam, Uma voz e nada mais (do original em inglês $A$ voice and nothing more), de Mladen Dolar (2012); A voz na clínica psicanalítica, de Jean-Michel Vivès (2012); e Voz do eco, de Erik Porge (2014). Ecos desses três livros podem ser encontrados ao longo de todo o texto a seguir, tendo em vista o norte que eles deram para o debate do cartel e para minha questão em particular.

Embora cada membro tenha percorrido o caminho sugerido por sua própria questão, marcou nosso cartel a interrogação da diferença entre o objeto voz para Lacan e os modos de sua recuperação como mais-de-gozar. Discussão fundamental que nos levou às passagens do próprio Lacan nas quais pudemos encontrar a natureza propriamente muda e perdida do objeto voz e a dimensão imaginária das manifestações da voz como recuperação de um objeto perdido, como mais-de-gozar, como tentarei desenvolver ao longo do próprio texto.

Devo muito aos meus amigos e colegas de cartel pela riqueza dos debates nesses dois anos e a oportunidade de avançar de modo tão bem acompanhado na pesquisa desse tema que ficou tão disperso ao longo da obra de Lacan e que, apesar disso, tem importância tão grande na clínica psicanalítica.

Passo, então, ao texto propriamente dito.

\section{O objeto voz em psicanálise}

Nesse nosso mundo, diversos são os filhotes que nascem dentro de sistemas compartilhados de códigos de comunicação. Do lobo à abelha, da libélula ao elefante. Há o mostrar os dentes e o empinar as orelhas entre um lobo alfa e um lobo ômega; há o twist pelo qual uma abelha sinaliza à sua comunidade o tipo, a direção e a distância de uma flor; há os rituais agonísticos entre libélulas macho e a posterior e ainda misteriosa escolha da libélula fêmea; e há os sinais de infrassom dos elefantes (vozes de baixa frequência, inaudíveis pelos humanos). Mas somente o filhote humano, até o momento, nasce dentro de um sistema de códigos cujos sentidos não são dados, mas abertos. Somente o filhote humano se depara com um sistema de sinais com uma potência inesgotável de significações.

Resultado disso é que o suporte material dos sinais de comunicação humana ganha uma importância singular enquanto configura algo do corpo que deve cair para que a significação enquanto tal advenha entre dois falantes. 
Se um bebê - atordoado ainda em sua inexperiência humana - chora, aqueles outros, não-bebês - atordoados já pela larga experiência humana - não poderão ouvi-lo, pois ao portarem uma concepção de sujeito falante atribuída ao bebê que chora, vão rapidamente impor-lhe ao grito a interpretação, o sentido, fazendo do grito enquanto tal, uma voz que se perde sob a violência da atribuição de um significado: Estará chorando de fome? Onde será que lhe dói? Do que não estará gostando? O que estará me pedindo? O que, enfim, ele quer dizer?

Em psicanálise, o sujeito é isso: um querer dizer que portamos ou colocamos no outro. E um choro, um grito, torna-se um choro para, um grito para. $O$ bebê se perde sob o significante em que seu grito se transforma. Significante que passa a representá-lo, num suposto querer dizer, não à mãe, posto que ela também se transforma num conjunto de significantes de onde o significante-grito - o signigritante - poderá extrair sentidos infindos. Entre o filhote humano e sua mãe, por estarem mergulhados na linguagem, já não há mais propriamente filhote e mãe, mas um significante que representa um querer dizer para outro significante que representa $o$ conjunto no qual este querer dizer encontraria um saber o que se diz. E o grito, enquanto mediação material desta dança de significantes, perde-se de seu estado de puro gozo, fora do simbólico, para entrar como aquilo que se esquece por trás do que se diz e naquilo que se ouve. Assim, é a voz, enquanto manifestação mítica de puro gozo, que cai quando o grito se transforma em signigritante. E que ela caia!, pois sem isso, o filhote não entra na experiência humana. É justamente pelo ato de tomar a palavra que o sujeito perde a voz. No fazer-se ouvir, o que então surge como sujeito passa a situar um grito perdido, à la Edvard Munch, para que a palavra possa se sustentar a partir de então. Na psicanálise, assim, encontramos a situação paradoxal do objeto voz ser mudo e estar sempre presente como o dizer impossível que se situa para que seja possível um dizer.

Drummond mostra bem saber da mudez da voz, ao terminar Menino chorando na noite com o retorno terrificante dela: "e vejo o fio oleoso que escorre pelo queixo do menino, / escorre pela rua, escorre pela cidade (um fio apenas). / E não há ninguém mais no mundo a não ser esse menino chorando."

Pois bem, de nada nos serviria postular a voz como objeto perdido se não fosse dos meios e efeitos de seu retorno, de sua recuperação, que a psicanálise tivesse que dar conta (entre outros objetos do mesmo modo resultantes do encontro da linguagem com um corpo gozante e do mesmo modo perdidos e recuperados em alguma medida).

Como suporte material do querer dizer, podemos encontrar algo da voz como aquilo que subsiste ao processo de significação. A voz é o que sobra ou o que excede ao querer dizer. Quando fazemos valer o querer dizer, ela soçobra, dado que, ao se atentar às nuances materiais da voz durante uma comunicação, distrai-se do sentido da mesma. Mas quando algo capenga no querer dizer, ela é excesso, um puro endereçamento, no qual o querer dizer se esfuma.

Temos, pois, que, em relação ao gozo, a voz é muda, é perdida (castração); e em relação ao desejo (ao querer dizer), ela é o sem sentido.

Que possamos falar da voz em sua materialidade, não é aí, no entanto, que a psicanálise vai localizá-la em sua função de objeto. A sonorização não passa de uma imaginarização, uma corporificação da voz. É uma encarnação à meia boca do objeto voz, mas que faz possível um pouco de seu gozo a quem reverbera e/ou a quem escuta (ou ausculta). 
Lacan menciona em mais de uma ocasião uma paciente psicótica que atendeu no hospital de Sainte-Anne. Essa mulher, que teria ouvido de seu vizinho - contra quem nada pesava - a injúria "porca", revelou a Lacan que, no momento anterior, teria pensado o seguinte: "estou vindo do salsicheiro". Paradoxalmente, na alucinada injúria sofrida por esta mulher os psicanalistas podem encontrar o júbilo da manifestação demonstrativa da existência do objeto voz.

Se o inconsciente é esta modulação contínua, este conjunto de cadeias que se impõem em busca da recuperação de experiências de satisfação que deixaram suas marcas significantes na história de um ser falante; se o inconsciente é este monólogo louco ao qual devemos ensurdecer para não ensurdecer; se o inconsciente é isso que em nós não desiste do gozo e fala, e fala, e fala, de sua perda, por sua perda, em sua busca, de sua busca; são então diversas as vozes que ali ecoam e com as quais temos que lidar. É assim que encontramos a injuriada paciente que, diante da frase "estou vindo do salsicheiro, logo: porca", pôde tomar para si e reconhecer como sua somente a primeira parte, atribuindo a segunda parte ao inocente do vizinho que, como Outro difamador, portou sem o saber um fragmento da cadeia significante carregado de conteúdo sexual e/ou da ameaça de despedaçamento do corpo. Por razões ligadas ao investimento libidinal do fragmento "porca", isto é, por seu valor de gozo, a mulher não o reconheceu como seu, fazendo-o ser dito pela voz do Outro.

Aí está: num pequeno acontecimento cercado pelos mistérios que podemos supor acerca dos desejos desta mulher pelo seu vizinho, uma voz sem qualquer materialidade sonora veio portar o dizer de um gozo por uma via que podemos chamar lacanianamente de real, embora fora da realidade e questionável quanto ao sentido (real porque fora do simbólico). E assim, como uma fala deslocada, uma voz sem som, um endereçamento de gozo, a voz como objeto se fez ouvir por um sujeito como efeito da negação radical de um significante (negação que Freud chamou de Werverfung - forclusão).

É assim, como parte de uma cadeia significante inconsciente que um sujeito não subjetiva, que o objeto voz vem assombrar os ouvidos dos seres habitados de linguagem.

Mas não precisamos ir assim tão longe e julgar que isto é coisa para loucos, pois, o que é o ato falho senão a intromissão numa fala de um fragmento de outra cadeia, de outras vozes que ali, em algum lugar naquele que fala, fala nele? Somente Freud pôde ouvir no ato falho tratar-se de um fragmento de um saber que habita o sujeito sem que ele o saiba. Freud pôde ver no riso, no desconcerto, no non sense, no estranhamento de quem fala inesperadamente o que não quer, as manifestações de afeto que apontam a alienação do sujeito em relação a um acontecimento de voz. Um ato falho é um querer dizer que o sujeito, por não reconhecer como seu, por alguma espécie de negação, atribui ao Outro no qual situa a experiência do inconsciente. Por que não pensarmos que algo do objeto voz se fez presente aí também, embora a materialidade sonora do ato falho nos faça pensar erroneamente na não mudez do objeto voz? Mas o fato é que, assim como na alucinação, algo que funciona como marca de gozo e que não foi subjetivado, é atribuído a Outro, escapando ao sentido. Um estranho querer dizer que se impõe ao sujeito como um saber demoníaco que goza nele. Um ser de gozo que volta e meia se reapresenta sem dizer quando e como vem, retornando do ostracismo ao qual o jogamos por nos julgarmos donos da palavra.

E as ruminações do obsessivo? Em que medida não se apresentam para ele como vozes de incômodas visitas ou insuportáveis possessões? Vale lembrar que, segundo Clérambault 
(apud PORGE, 2014), no automatismo mental a voz é o pensamento que se torna estrangeiro. E por que não pensarmos que este estrangeirismo do pensamento pode se dar em diversos níveis e formas que vão da exclusão à extravagância?

Também na interpretação, sempre a mesma, dos mais diversos ditos dos outros - o que no jargão entrou indevidamente pela via imaginária da projeção - encontramos a sombra de uma voz que insiste, que invade, que se faz Outra em relação ao sujeito que sofre de seu estranho, porém familiar, endereçamento, como um mal-dito eco.

Tomemos agora, como exemplo, o insulto. Não o de há pouco, alucinado. Mas o insulto cotidiano, do trânsito, das más educações, das irritações e indignações cotidianas. O que encontramos ali? $\mathrm{Na}$ polpa do palavrão, o insulto propaga a peste que contamina o ouvinte. Xingar é endereçar ao outro mais do que um significante. No significante xingado, o sentido pouco importa. (Lembremos, como exemplo, dos insultos dirigidos por Ernst Lanzer - o Homem dos Ratos - ao pai após uma surra: "Sua lâmpada! Sua toalha! Seu prato!" (FREUD, 1909/1996, p. 179-180)) O que se atira no outro dentro da palavra é mais do que a palavra. O palavrão assim o é porque carrega o peso do gozo de quem xinga. É uma imposição significante na qual o excesso de voz, a vociferação, conta mais do que um querer dizer que seria apropriado ao processo de significação. Como efeito, a injúria pode atingir o outro na sua posse da palavra, destituindo-o de seu querer dizer e colando-o, alienando-o ao dejeto cujo efeito de sentido os termos da injúria veicula. Se o Outro original, que supomos haver na mãe, atribui ao filhote humano vivo um sujeito, este Outro que xinga e urra, no qual geralmente colocamos a face mais perversa do pai, nega o sujeito no outro. Por que não haveria aí, nesta dimensão de gozo que excede o simbólico da palavra, um dos retornos assustadores do objeto voz? Na clínica psicanalítica sabemos bem de que modo os melancólicos proliferam a dimensão do insulto contra si mesmos, como forma absurda e por vezes delirante de dar um sentido à sua experiência de ser um dejeto (chegam até a provocar o outro de modo a extrair dele qualquer palavrão confirmador de sua estranha posição de gozo).

Se o obsessivo recupera o objeto voz pela ideia intrusa, o melancólico o faz pelo insulto conquistado ou repetido.

Pois bem: não é justamente nessa injunção de gozo de um suposto pai perverso que podemos reconhecer o que a psicanálise chama de supereu?

$\mathrm{O}$ supereu, enquanto instância psíquica êxtima - ou seja: topologicamente interna e externa ao mesmo tempo -, na medida em que se desprende dos suportes simbólicos e imaginários do ideal de eu, se apresenta em sua dimensão real, de gozo, como voz que pune, que censura, que impede, que impõe, abdicando de qualquer significação que não seja puro pretexto que venha colorir, racionalizar, preencher o sem sentido da injunção. Como voz atribuída ao Outro e não reconhecida pelo sujeito, o supereu é a absolutização da autoridade alheia e a desautorização subjetiva extrema. É a voz da hipnose que, quando ecoa socialmente, na política, na religião ou no mercado, põe em risco muito ou tudo que a cultura - que não resulta senão do querer dizer - pode sustentar como meio de eternizar os sujeitos e os ditos que estes fizeram existir. Como recuperação do objeto voz, e guardada, é claro, todas as causas objetivas que lhe acompanham, a coletivização do supereu perverso destitui os sujeitos em larga escala, alcançando até mesmo os significantes que os representam em sua condição de sujeitos sem corpo, como obras de arte, monumentos, lápides, mementos e outros. 
(Aliás, quando uma boa parte da população de uma cidade começa a andar com fones de ouvido é preciso perguntar não somente o que ela está ouvindo, mas também o que ela não quer ouvir. $\mathrm{Na}$ era da resposta imediata, da pesquisa instantânea, da reportagem online, das comunicações e transmissões simultâneas, dos localizadores e rastreadores absolutos, das redes hiperconectadas, das webcams multiespalhadas, dos nubilosos arquivos eternizados de coisas eletronicamente escritas, enfim: neste mundo de olhos sempre abertos e vozes que nunca se calam, o anonimato da massa, o esconderijo do quarto fechado, os óculos escuros e os fones de ouvido são, para o sujeito, momentos de trégua e descanso.)

O retorno do objeto voz, ao sujeito, vem sempre nalguma forma de retorno da voz, como um eco, um endereçamento que lhe volta, mas, às vezes, como não lhe tendo saído. É um reverberar do qual, em diferentes níveis (alucinados, obsessivos, ruminantes, demandantes, superegóicos, chistosos, poéticos, melódicos, ato-falhados), se apaga o re-. Uma voz que (re)verbera - verbera com o re posto entre parênteses. Por isso, um eco mal-dito; daí o seu caráter parasitário.

\section{O lugar da função poética na poli(a)fonia do objeto voz}

Passemos agora à função poética e sua relação com o objeto voz.

Numa certa altura de seu Seminário 11, Lacan (1964/1990) se recusa a conceber o pintor pelo viés narcisista, como alguém cujo querer dizer pela pintura implicaria o desejar ser visto. Numa bela análise, pela qual situa o fazer do pintor a partir da composição dos gestos de depósito de tinta sobre uma tela (algo que remeteria antes aos desejos de manipulação do cíbalo do que de recuperação do olhar), Lacan apresenta o pintor como alguém cujo mérito é apaziguar o olhar. Se o olhar - que também, como um objeto perdido, retorna pela recuperação assombrosa de gozo - panopticamente oprime o sujeito da paranoia, vigia o sujeito da culpa, procura a mascarada histérica ou goza com o exibicionismo narcisista, um meio de apaziguá-lo é dar-lhe pasto ao gozo. Por isso Lacan coloca o pintor como aquele que propõe: "Queres olhar? Pois bem, então veja isso!” (p. 99). O Outro depõe ali seu olhar, suas armas, seu gozo.

O que seria o equivalente para o objeto voz? A música? O canto? A poesia?

A poesia, a melodia, não seriam um engana-voz, assim como o quadro é um enganaolhar (trompe l'oeil)? Queres invocar? Vocalize isto!

Rachimaninoff compôs seu Vocalise, seu pasto para o vociferar. Bach, por sua vez, já havia "cantado" algo semelhante na sua ária na corda sol (que originalmente é uma composição para orquestra e em ré) e Villa-Lobos juntou tudo isso é fez a ária da Bachiana n. 5 (um verdadeiro apaziguador do objeto voz!).

Mas, e na poesia? Não seria o poeta um pintor de palavras? Desejariam todos os poetas narcisicamente ser ouvidos? Não creio. Pensando, com a psicanálise, além do que objetivamente os poetas desejam transmitir, creio que o fazer do poeta aponta - em equivalência ao do pintor - para um meio de domesticar e apaziguar as faces (ou tonalidades) assombrosas do retorno do objeto voz. E o que o poeta traz em sua paleta? A materialidade sonora. O quadro da poesia é feito da composição de fonemas e silêncios. Há no ato do poeta um fazer-se ouvir de uma voz que se possa recuperar em sua materialidade enquanto efeito (acréscimo) de sentido e endereçada ao Outro. É uma voz de sedução (de afetação, no 
mínimo), acrescida à comunicação de algo. Está em jogo na poesia mais do que o pendor para a mensagem (como propôs Jakobson (1960/2008)), há também o endereçamento silenciador do Outro, no acréscimo de sentido promovido pela materialidade sonora. É por convocar o afeto nas cores de sua fala que o poeta cala o Outro do gozo.

Neste endereçamento feito de acréscimo de sentido, podemos propor a presença de um sujeito suposto desejar que, por esta feita, não se apresenta pela alienação a um significante, mas sim, se faz reconhecer no próprio processo de significância, entendida como potência aberta de sentido e não como significação cristalizada.

O poema, assim como o canto, pede ao Outro que deponha suas defesas e se entregue ao deleite material da voz, dos fonemas, dos sons das palavras para além de seus sentidos. A vocação do poeta, assim como a do cantor, é emudecer as sereias ou, de outro modo, transmutar a feroz vociferação em doce sussurro, como podemos ver, de modo alegórico, num poético trecho bíblico:

E Deus disse: sai, e põe-te neste monte perante o Senhor e eis que passava o Senhor, como também um grande e forte vento que fendia os montes e quebrava as penhas diante do Senhor; porém o Senhor não estava no vento; e depois do vento um terremoto; também o Senhor não estava no terremoto; e depois do terremoto um fogo; porém também o Senhor não estava no fogo; e depois do fogo uma voz mansa e delicada. (I REIS, 19:11-12)

Na poesia e no canto, a voz se torna ars entre oris e auris (ou seja: arte entre boca e ouvido).

Para a interpretação psicanalítica, a concepção de um objeto voz e o entendimento da lógica que opera na função poética são fundamentais. De um lado, o silêncio do analista produz uma hiância, uma abertura, lá onde o analisante esperaria a presença de uma resposta, isto é, uma significação. Por esta abertura assim produzida passam as manifestações dos objetos que este analisante fez existir e as significações que ele extraiu do Outro para dar consistência ao seu existir. É aí que a interpretação analítica intervém, seja para esvaziar o gozo condensado nestes objetos, seja para suspender (contra-significar) as significações cristalizadas e alienantes pelas quais o analisante sustenta um pouco de ser fazendo-se de objeto para o gozo do Outro.

A lógica que opera na função poética pressupõe a suspensão da binaridade do juízo, que reduz toda significação necessariamente à falsidade ou à veracidade. Diante da infinitização das significações possíveis dentro da linguagem poética (que não se reduz unicamente à poesia!), o efeito é justamente o da potência de sentido, abrindo o juízo de uma proposição a um valor que não se deixa reduzir ao verdadeiro ou ao falso próprios a outras modalidades de linguagem e/ou comunicação. Por essa via, a interpretação não visa tomar o sujeito como o que se reconhece por um significante isolado, mas tomá-lo pelo próprio processo de significância, que supõe uma abertura, uma suspensão, uma descoagulação dos significados fechados. Esse processo recoloca em jogo um furo de sentido no qual localizamos aquilo que se perde em gozo para que o desejo se sustente enquanto manifestação de um ser de linguagem, de um ser que se satisfaz lançando-se no mundo como um inventor, criador, produtor, fazedor de sentidos.

No furo da significância, o que se localiza como perdido é o objeto voz, aquilo que não pode ser dito para que o dizer se sustente. 
A interpretação analítica, assim, não dá sentido, mas destampa o furo do sentido, ao abrir a torneira do tonel de significações do ser falante, insistindo em apontar que o objeto voz não está lá, ou seja, ao levar o analisante a se deparar com o fato de que o Outro de gozo é mudo, mas que ele é habitado por um saber que goza de brincar de marcar seu corpo com a língua, o que faz, nele, os afetos.

O corpo é marcado de ecos de afetos, que vão do terror do grito ao prazer dos gorjeios de berço, passando pelo conforto da voz materna e pelo medo da voz do pai, pelo encanto do gemido da amante e pelo enigma do silêncio do analista. E podemos ainda listar impressões afetivas, tais como o tranquilizante veludo do timbre da avó, a taquara rachada da irritante vizinha, a desafinada e engraçada professora... Até mesmo a fala sem variações de tonemas e pausas de mesma duração dos aparelhos robotizados, como o HAL 9000 do 2001 de Kubrick, nos causam um estranho sentimento de que estamos diante da desumanização, e não do não-humano.

$\mathrm{O}$ analista escuta, antes dos sentidos, ou debaixo deles, os hipogramas, as homofonias, as escansões silábicas. O analista ouve a polifonia na associação livre, munido, portanto, da função poética. De outro modo ele não poderia, diante da fala "vivo numa tamanha inutilidade", recombinar sons, silêncios e sentidos e interpretar: "não mata a mãe, inutilidade".

Num outro exemplo clínico, um analisante se queixava das cobranças de seu tempo presente e mencionou a saudade dos balanços das casas de sua infância. Foi apontado que ele podia fazer novamente das cobranças, balanços (observando-se que oito das nove letras da primeira palavra estão presentes entre as sete das oito letras da segunda palavra). Surpreendente efeito! Este analisante cessou de escrever suas cobranças e decidiu-se a mudar da casa dos pais para morar com a companheira, com quem se permitiu balanços que antes não lhe causavam tanto prazer.

O analista escuta as ressonâncias, os ecos, os anagramas, que lhe permitem ouvir no analisante queixando-se da mãe fálica - "minha mãe o tempo inteiro x; minha mãe o tempo inteiro y; minha mãe o tempo inteiro z" - o subtexto minha mãe tem pinto ("minha mãe o tempo inteiro..."), assim como Ferdinand de Saussure leu em Circuresque de um verso o anagrama de Circe. Ou como em Nova poética, poema no qual lança "a teoria do poeta sórdido", Manuel Bandeira espalha as letras da palavra sórdido no verso "o poema deve ser como a nódoa no brim".

O próprio Daniel Paul Schreber - o iminente jurista alemão nomeado pelo próprio rei para juiz - presidente da Corte de Apelação da cidade de Dresden em 1893, mas que fícou famoso por suas Memórias de um doente dos nervos, nas quais descreve pormenorizadamente cada um dos elementos de seu delírio psicótico - fez uso das ressonâncias homofônicas e anagramáticas de suas alucinações auditivas como forma de confundir as fontes de sua alucinação e divertir-se em meio à desolação de sua loucura. Assim ele escreveu sobre os pássaros miralucados cujos raios-vozes jogavam com a função poética:

Como foi dito, os pássaros não entendem o sentido das palavras que falam; mas, ao que parece, eles têm uma sensibilidade natural para a assonância. Por isso, se enquanto estão ocupados em tagarelar as frases decoradas percebem palavras que têm um som igual ou próximo daquele que no momento estão falando (tagarelando), seja nas vibrações provenientes dos meus próprios nervos (meus pensamentos), seja pelo que é dito no meu ambiente, isto os deixa em um estado de surpresa em consequência do qual, eles, por assim dizer, sucumbem à assonância, isto é, por causa da surpresa 
eles esquecem o resto das frases que ainda tinham para tagarelar e passam subitamente para uma sensação autêntica.

Como se disse, a assonância não precisa ser total; uma vez que não captam o sentido das palavras, basta que percebam sons semelhantes; para dar alguns exemplos, para eles pouco importa que se diga: "Santiago" ou "Cartago" "Chinesentum" ou "Jesum Christum", "Abendrot" ou "Atemnot", "Ariman" ou "Ackerman", "Briefbeschwörer" ou "Herr Prüfer schwört", etc., etc. (SCHREBER, 1905/1984, pp. 144-5)

A pena do alucinado jurista esclarece a quem quiser ouvir que os poéticos pássaros miraculados schreberianos não captam o sentido das palavras, mas são sensíveis aos sons semelhantes.

Como não pensar que a modulação contínua, em que se configura o inconsciente, fale a língua dos miraculados pássaros tão sofridamente descobertos por Schreber? E como não pensar que, para ouvi-los, se não loucos, temos que assear os ouvidos às assonâncias que se nos compulsa a poesia da fala solta na qual encontramos a associação livre?

Poderiam ser lobos ou abelhas, libélulas ou elefantes, mas deu em Daniel Paul Schreber de botar o retorno da voz em bichos que cantam. Por isso, façamos uso de sua poesia para dizer que os pássaros miraculados somos nós, enquanto seres que sucumbimos às assonâncias nascidas da estranha satisfação do inconsciente que se modula em corpo nas cirandas significantes que surgem em torno da afonia de uma voz perdida. Façamos, pois, uso disso, para que possamos ser, se não poetas, poemas, falados que somos desde esse saber que goza de pôr palavras lá onde uma voz se cala.

\section{Pequena síntese e conclusões}

Para finalizar, arrisco-me a um breve resumo.

No lugar de um impossível significante, portador de um sentido último para o sujeito, inventa-se um resto, um objeto que, no que diz respeito à pulsão invocante, se apresenta como voz. Isto equivale a dizer que o sujeito, ao falhar nas tentativas de se nomear a partir do Outro, realiza-se no objeto que ali advém como suplência. Seu ser se faz voz, como objeto que se delimita a partir de uma pulsão, lembrando que a pulsão - e segundo a invenção de Freud - é o que resulta do encontro entre linguagem e corpo, entre desejo e sexualidade, e que se manifesta a partir de uma estrutura de borda - daí a voz se fazer objeto caído de um corte feito pela emissão de um orifício: a boca. Na escansão da fala, a voz se faz do obus da boca. Sem ser o som, nem o rastro da respiração, a voz é projétil suposto do ato da emissão, que por se dar no laço social, é também endereçamento. A voz é evento que une falante e ouvinte, que separa falante e ouvinte, e que não é nem o falante nem o ouvinte. Ela transiciona (como percebeu Winnicott). Entre dois significantes (aos quais se reduzem falante e ouvinte) o sujeito se representa, mas nesse vão, a voz é inter: inter-valo, que um querer dizer produz. Um obus vazio entre dois orifícios: o lugar do significante de uma falta e o lugar da falta de um significante. Para preencher este obus vazio, trazemos diversas vozes: a injunção superegóica, o delírio psicótico, a demanda insaciável, a ideia invasora, a consciência pesada, a ruminação parasita, mas também o canto, a música, a poesia (e, quem sabe, o jogar conversa fora).

Se o filhote humano, ao ser tomado pela linguagem, encontra um indizível que se manifesta pelo furo que o objeto voz estrutura, é justamente da presença desta condição formal que podemos inventariar as diversas modalidades de suplência deste furo, ou seja, de retorno 
de alguma consistência sintomática no lugar suposto pela afonia da voz. Há algo, pois, em comum, ao menos para a psicanálise, entre a alucinação, a injunção, a ideia obsessiva, o canto e a poesia. São todos tentativas, ao mesmo tempo, de dar corpo à voz, e de dar voz ao corpo.

Do grito de apelo ao riso de satisfação, do assobio ao balbucio, da tosse de quem pede a palavra ao soluço de quem a adia (como ocorreu a Aristófanes), do ranram de quem prepara a garganta ao hum-hum de quem consente, no tique fungado, suspirado, grunhido, estalado..., são muitos os sons que, entrando ou não no conjunto dos fonemas, não deixam de ser sinais de endereçamento, não deixam de ter valor significante e, portanto, não deixam de ser coisas lançadas da boca de um querer dizer em busca de um sentido qualquer que se articule do encontro de outro significante que a língua faça existir em seu portador-ouvinte. Uma vez que a voz se faça estruturalmente objeto perdido, não há emissão significante que não carregue um enigma, não há endereçamento não atravessado pelo oracular, não há comunicação em que o equívoco não seja possível. Com a queda da voz, um Outro que fala em mim se torna um fato incontornável e, os modos contingentes que encontro para contornar sua voz, tornam-se os fundamentos da minha vocação. E isso responde pela singularidade de cada um.

\section{Referências bibliográficas}

BANDEIRA, M. Nova poética. Disponível em: < http://lituraterre.com/2011/02/13/nova-poetica-por-manuelbandeira-2/http://ituraterre.com/2011/02/13/nova-poetica-por-manuel-bandeira-2/>. Acesso em 06 de set. 2014.

DOLAR, M. Une voix et rien d'autre. Caen (França): Nous, 2012.

FREUD, S. (1909). Notas de um caso de neurose obsessiva. In: Obras psicológicas completas de Sigmund Freud: edição standard brasileira. Volume X. Rio de Janeiro: Imago, 1996, pp. 137-276.

Goethe, J. W. (1808). Fausto: uma tragédia - primeira parte. Tradução de Jenny Klabin Segall. São Paulo: Editora 34, 2011 162.

JAKOBSON, R. (1960). Linguística e poética. In: Linguística e comunicação. São Paulo: Cultrix, 2008, p. 118247.

LACAN, J. (1964). Ato de fundação. In: Outros escritos. Rio de Janeiro: Jorge Zahar Editor, 2003, pp. 235-

J. (1964). O Seminário, livro 11: os quatro conceitos fundamentais da psicanálise. Rio de Janeiro: Jorge Zahar Editor, 1990.

PORGE, E. Voz do eco. Campinas, SP: Mecado de Letras, 2014.

SCHREBER, D. P. (1905). Memória de um doente dos nervos. Rio de Janeiero: Edições Graal, 1984.

VIVÈs, J.-M. A voz na clínica psicanalítica. Rio de Janeiro: Contra Capa/Corpo Freudiano seção Rio de Janeiro, 2012. 